\title{
The Assessment of Fixed Orthodontic Treatment Successfulness Using American Board of Orthodontics System in Airlangga University Dental Hospital
}

\author{
I Gusti Aju Wahju Ardani, Dimas Iman Nugroho, Fakhma Zakki Ramadhani and Ida Bagus Narmada \\ Department of Orthodontics \\ Faculty of Dental Medicine, Universitas Airlangga \\ Surabaya, Indonesia.
}

\begin{abstract}
Background: The purpose of orthodontic treatment is to improve efficient function, tissue balance, and obtain harmonious facial aesthetic results so the successfulness of orthodontic treatment should be comprehensive because maloclusion can occur in dentoalveolar, skeletal and soft tissue tissues. Purpose: This study aims to evaluate the successfulness of orthodontic treatment using fixed orthodontic appliances in Orthodontic Clinic Dental Hospital, Faculty of Dental Medicine Universitas Airlangga by means of ABO system. Methods: Descriptive analytic by comparing the data before and after treatment, then the sample was divided into 3 based on the skeletal malocclusion group. Dental efficacy was measured using the ABO system and the Bolton anterior ratio. Skeletal success by looking at ANB, FHI, and proportion of anterior facial height (UAFH: LAFH). Meanwhile, the success of the soft tissue was by seeing the changes in the aesthetic lines of the upper and lower lips. The statistics used in this study were Kruskal-Whallis for the ABO DI and OGS difference test, Spearman to determine the relationship between ABO DI and OGS measurement components and McNemar and Wilcoxon to determine the difference before and after treatment on all measurements. Results: Treatment of class I skeletal malocclusion had the best mean ABO OGS score. Class II and III treatments had significant treatment advancements. In other measurements, there are significant differences after treatment at FHI in class I, (UAFH: LAFH) in class II and lower lip esthetic line in class II. Conclusion: Generally, the successfulness of orthodontic treatment in Orthodontic Clinic Dental Hospital, Faculty of Dental Medicine, Universitas Airlangga was adequate. In addition, the assessment of the successful orthodontic treatment needs to be adjusted to the standard values that can be accepted by a certain population, especially the Javanese population.
\end{abstract}

Keywords: ABO; malocclusion; orthodontics; treatment success

Correspondence: I Gusti Aju Wahju Ardani, Department of Orthodontics, Faculty of Dental Medicine, Universitas Airlangga. Jl. Mayjend Prof Dr Moestopo, No 47, Surabaya 60132, Indonesia, Email: wahju_ardani@fkg.unair.ac.id

\section{INTRODUCTION}

Diagnosis in the field of orthodontics greatly affects the success of orthodontic treatment. Moyers states that orthodontic diagnosis is a systematic estimate, temporary, accurate and aimed at 2 things: classification and treatment plan. ${ }^{1,2}$

The main purpose of orthodontic treatment is to correct abnormal relation and malformation of dentocraniofacial structure, obtain harmonious occlusion both its location and function and also to create a balance between the occlusal relationship of amused teeth, aesthetics of the face and the stability of the treatment results. ${ }^{1,3}$

The American Board of Orthodontics (ABO) developed 2 assessment systems namely discrepancy index (DI) for pretreatment assessment and Objective Grading System (OGS) for post-treatment assessment. The ABO discrepancy index (DI) was developed by the American Board of Orthodontics (ABO) to measure the complexity of orthodontic cases based on measurements of study models and radiographic prior to treatment. $^{4,5}$

A good amusing relationship of the upper jaw and lower jaw can affect the stability of orthodontic treatment results. This is certainly one of the main goals of orthodontic treatment. Bolton introduced a mathematical method for obtaining discrepancy information on the size of teeth between amused arches. Bolton found that if the anterior amusing ratio of the upper jaw and lower jaw to achieve good interdigitation was $77.2 \%$, $^{6,7}$

The success of the treatment is not only seen in terms of dental alone. The success of the treatment that is in accordance with the purpose of orthodontic treatment is also 
seen in terms of skeletal and soft tissue changes, especially in class II and III cases. Success in terms of skeletal can be measured by looking at the changes in skeletal discrepancy i.e., large changes in an ANB angle. In addition, a mallocation can occur in vertical and anteroposterior directions. One of the most commonly used methods is to measure changes in the height proportion of the upper front face (Anterior Upper Face Height) and lower (Anterior Lower Face Height $)=(\mathrm{UAFH}: \mathrm{LAFH})$; as well as high proportions of the posterior face (Posterior Face Height) and anterior $($ Anterior Face Height $)=(\mathrm{PFH}: \mathrm{AFH}){ }^{8}$

Soft tissue profiles have a significant role in the diagnosis and treatment of orthodontics. The facial profile is one of the important objectives in orthodontic care because the attractiveness of the patient's face has a psychosocial effect that is accepted and felt by the community. The simplest method of checking the lower third of the face is Ricketts' aesthetic line by connecting the upper and lower lips with tangential drawn lines against the nose and chin. ${ }^{9}$

\section{MATERIALS AND METHODS}

This study was an observational analytic cross-sectional study. The study protocol was approved by ethical clearance of Faculty of Dental Medicine, Airlangga University, Surabaya Indonesia with appointment number 634/HRECC. FODM/X/2019.

The samples used in this research were patients who have completed orthodontic treatment from January 2017 to December 2018. Patient data required in this study was study model, lateral cephalometry before pre- and posttreatment at Orthodontic Clinic of Airlangga University Dental Hospital. In the period January 2017- December 2018144 patients had completed orthodontic treatment at the Orthodontic Clinic of Airlangga University Dental Hospital, but the sample that can be included in the inclusion and exclusion criteria was 95 samples because there are some patients who do not have complete data. After that, the entire sample was divided into 3 groups according to the malocclusion group. Basically, this study compares the data before and after treatment. ABO DI and OGS were measured with ABO measuring gauge (Figure 1). Bolton anterior analysis measured with a digital caliper (Figure 2). Cephalometric were analyzed by digital cephalometric Orthovision 2017.

All data obtained were examined by averages of Statistical Package for Social Science (SPSS) 20.0 version (IBM Corporation, Illinois, Chicago, US). Kruskal-Whallis $(\mathrm{p}<0.05)$ analysis was done to examine the significant difference between ABO DI and ABO OGS. McNemar and Wilcoxon analysis $(\mathrm{p}<0.05)$ was done to find out the success of the treatment.

\section{RESULTS}

ABO DI measurements showed that class III (20.04) skeletal malocclusion got the most difficult average followed by class II (19.37) and class I (12.57). Meanwhile, in ABO OGS measurement showed that class I (18.93) skeletal malocclusion had the best average treatment result followed by class III (20.75) and class II (22.93). In the statistical test, there were significant differences in class II and III malocclusion. The average anterior Bolton ratio before and after was relatively constant in class II and III while in class I, it shows an average decrease. Statistical test results showed no significant differences before and after treatment in malocclusion class I, II, and III. In the ANB measurement before and after treatment, the averages improved in class I, II, and III although statistically only significant in class II. In FHI measurements obtained a normal average at the end of treatment in all classes although statistically there were significant differences only in class I. While in the measurement (UAFH: LAFH) there were statistically significant differences in class II. In class II there was an average increase in the height of the lower anterior face at the end of the treatment. In the measurement of E-line before

Table 1. Pre- and post-treatment measurements in class I, II and III malocclusion patients

\begin{tabular}{|c|c|c|c|c|c|c|c|c|}
\hline \multirow{2}{*}{ Variable } & \multirow{2}{*}{ Class } & \multicolumn{3}{|c|}{ Pre } & \multicolumn{3}{|c|}{ Post } & \multirow{2}{*}{$P$ value } \\
\hline & & $\mathrm{N}$ & Mean & SD & $\mathrm{N}$ & Mean & SD & \\
\hline \multirow{3}{*}{$\mathrm{ABO}$} & I & 44 & 12.57 & 2.95 & 44 & 18.93 & 1.34 & 0.32 \\
\hline & II & 27 & 18.93 & 4.46 & 27 & 22.93 & 3.09 & 0.00 \\
\hline & III & 24 & 19.37 & 4.41 & 24 & 20.75 & 1.80 & 0.00 \\
\hline \multirow{3}{*}{ Anterior Bolton Ratio } & I & 44 & 77.76 & 1.81 & 44 & 76.71 & 6.98 & 0.69 \\
\hline & II & 27 & 77.64 & 1.14 & 27 & 77.64 & 1.14 & 1 \\
\hline & III & 24 & 77.46 & 1.7 & 24 & 77.46 & 1.7 & 1 \\
\hline \multirow{3}{*}{ ANB } & I & 44 & 2.50 & 0.55 & 44 & 2.45 & 0.59 & 1.00 \\
\hline & II & 27 & 5.44 & 1.62 & 27 & 4.44 & 1.05 & 0.06 \\
\hline & III & 24 & -2.42 & 1.79 & 24 & -1.17 & 1.1 & 0.12 \\
\hline \multirow{3}{*}{ FHI } & I & 44 & 0.65 & 2.48 & 44 & 0.65 & 2.4 & 0.04 \\
\hline & II & 27 & 0.66 & 2.45 & 27 & 0.66 & 2.41 & 0.5 \\
\hline & III & 24 & 0.64 & 1.49 & 24 & 0.65 & 2.48 & 1 \\
\hline \multirow{3}{*}{ UAFH (\%) } & I & 44 & 45.62 & 2.46 & 44 & 45.65 & 4.64 & 0.45 \\
\hline & II & 27 & 45.1 & 3.38 & 27 & 44.7 & 3.11 & 0 \\
\hline & III & 24 & 45.35 & 2.41 & 24 & 45.58 & 3.38 & 1 \\
\hline \multirow{3}{*}{ LAFH (\%) } & I & 44 & 54.35 & 3.24 & 44 & 54.4 & 3.76 & 0.45 \\
\hline & II & 27 & 54. 45 & 3.96 & 27 & 54.81 & 3.43 & 0 \\
\hline & III & 24 & 54.59 & 2.45 & 24 & 54.37 & 3.65 & 1 \\
\hline \multirow{3}{*}{ E-Line (Upper) } & I & 44 & 0.45 & 2.07 & 44 & 0.22 & 2.64 & 0.37 \\
\hline & II & 27 & 2.81 & 2.38 & 27 & 1.03 & 2.49 & 0.12 \\
\hline & III & 24 & -2.1 & 2.41 & 24 & -1.91 & 2.34 & - \\
\hline \multirow{3}{*}{ E-Line (lower) } & I & 44 & 1.25 & 2.24 & 44 & 0.8 & 2.32 & 1.00 \\
\hline & II & 27 & 3.55 & 2.96 & 27 & 1.33 & 2.68 & 0 \\
\hline & III & 24 & 0.45 & 2.45 & 24 & -1.45 & 2.36 & 0.28 \\
\hline
\end{tabular}


Indonesian Journal of Dental Medicine Volume 4 Issue 1 2021; 1-5

Table 2. Differences in ABO DI scores among patients with skeletal malocclusion class I, II and III for each measurement components with Kruskal-Wallis test analysis

\begin{tabular}{lccccccc}
\hline \multirow{2}{*}{ Components } & \multicolumn{9}{c}{ ABO DI Malocclusion Score } & \multicolumn{2}{c}{ Class III } & \multirow{2}{*}{ P value } \\
\cline { 2 - 6 } & Averages & SD & Averages & SD & Averages & SD \\
\cline { 2 - 6 } & 2.07 & 0.69 & 3.00 & 0.00 & 4.67 & 1.93 & 0.00 \\
Overjet & 2.32 & 0.60 & 3.00 & 0.00 & 0.25 & 0.68 & 0.00 \\
Overbite & 0 & 0 & 0 & 0 & 3.50 & 1.35 & 0.00 \\
Anterior Open Bite & 0 & 0 & 0 & 0 & 0 & 0 & 1.00 \\
Lateral Open Bite & 5.82 & 1.63 & 2.00 & 0.00 & 2.37 & 2.45 & 0.00 \\
Crowding & 0.73 & 0.97 & 7.11 & 1.01 & 4.50 & 1.35 & 0.00 \\
Occlusal Relationship & 0 & 0 & 0 & 0 & 1.83 & 0.56 & 0.00 \\
Lingual Posterior X-Bite & 0 & 0 & 0.74 & 1.58 & 0 & 0 & 0.00 \\
Buccal Posterior X-Bite & 0 & 0 & 1.37 & 2.80 & 0.92 & 2.48 & 0.01 \\
Cephalometric & 1.95 & 0.48 & 2.18 & 0.396 & 2.00 & 0 & 0.03 \\
Other & 12.57 & 2.95 & 19.37 & 4.465 & 20.04 & 4.41 & 0.00 \\
ABO DI Total Score & & & & & & & \\
\hline
\end{tabular}

Tabel 3. Differences in ABO OGS scores among patients with skeletal malocclusion class I, II and III for each measurement components with Kruskal-Wallis test analysis

\begin{tabular}{|c|c|c|c|c|c|c|c|}
\hline \multirow{3}{*}{ Components } & \multicolumn{6}{|c|}{ ABO OGS Malocclusion Score } & \multirow{3}{*}{$P$ value } \\
\hline & \multicolumn{2}{|c|}{ Class I } & \multicolumn{2}{|c|}{ Class II } & \multicolumn{2}{|c|}{ Class III } & \\
\hline & Averages & $\mathrm{SD}$ & Averages & $\mathrm{SD}$ & Averages & $\mathrm{SD}$ & \\
\hline Alignment & 3.41 & 1.08 & 3.96 & 1.34 & 2.83 & 1.24 & 0.01 \\
\hline Marginal Ridges & 3.59 & 0.69 & 4.67 & 1.24 & 2.96 & 0.95 & 0.00 \\
\hline Buccolingual Inclination & 3.39 & 1.02 & 2.41 & 0.69 & 1.58 & 0.83 & 0.00 \\
\hline Overjet & 3.41 & 0.92 & 4.44 & 1.28 & 3.58 & 0.83 & 0.00 \\
\hline Occlusal Contacts & 2.00 & 1.76 & 1.04 & 1.16 & 4.08 & 1.91 & 0.00 \\
\hline Occlusal Relationships & 1.14 & 0.95 & 4.22 & 2.62 & 3.50 & 1.32 & 0.00 \\
\hline Interproximal Contacts & 1.30 & 0.98 & 1.15 & 1.23 & 1.46 & 1.69 & 0.73 \\
\hline Root Angulation & 0.77 & 0.86 & 0.85 & 0.91 & 0.54 & 0.66 & 0.50 \\
\hline ABO OGS Total Score & 18.92 & 1.34 & 22.93 & 3.09 & 20.75 & 1.80 & 0.00 \\
\hline
\end{tabular}

and after treatment, the improvement results were obtained in all classes although statistically there were significant differences in the lower lip on class II malocclusion (Table 1).

The results of the 10 different ABO DI components in each class had significant differences except in the lateral assessment component of the open bite because there were no cases with lateral open bite abnormalities. Components with the highest average value in class I malocclusion are crowding followed by overjet and overbite. Components with the highest average value in class II malocclusion are occlusal relationships followed by overjet and overbite. Components with the highest average value in class III malocclusion are occlusal relationship and overjet followed by anterior open bite (Table 2 ).

In this study showed that in class I malocclusion: the components that have the highest score on are marginal ridges followed by alignment and overjet. In class II malocclusion: the components that have the highest score are marginal ridges followed by overjet and occlusal relationships. In class III malocclusion, the components that have the highest component are occlusal contacts followed by overjet and occlusal relationships (Table 3 ).

\section{DISCUSSION}

There are several methods to measure the success of an orthodontic treatment. The most commonly used are PAR
Index and ABO System. PAR Index is often used to measure the progress of orthodontic treatment in Europe, while the ABO System is often used to determine the standard for an orthodontist in completing an orthodontic treatment in America. Hong et al. argue that the ABO has a more detailed treatment result assessment system than the PAR Index. The ABO assessment system is carried out pointby-tooth assessment while par index applies assessment per segment. $^{10}$

ABO DI was used to determine the severity of orthodontic cases by measuring the pre-treatment study model. The easy category is DI score $<16$, medium 16-25 and difficult $>25{ }^{11}$ The results of the ABO DI study showed that each of the malocclusion has different characteristics. In this study, overjet and overbite were among the components with the highest average values in class I, II, and III malocclusions. This is due to in the ABO DI scoring system, the addition of points on the overjet measurement component are cases with overjet has more than $3 \mathrm{~mm}$ and less than $1 \mathrm{~mm}$. The addition of points on the overbite measurement component is carried out in cases with an overbite of more than $3 \mathrm{~mm}$. This could be because most of the study subjects were Javanese races that had an average overjet frequency of $3-5 \mathrm{~mm} .{ }^{11,12}$

ABO OGS was used to determine the success of orthodontic treatment by measuring the post-treatment study model. There are 3 categories in ABO OGS: successful, imperfect, and failed. The successful category is OGS score $<20$, imperfect 20-30 and failed $>30 .{ }^{13,14}$ Overjet is one of the measuring components that has the highest score in 
malocclusion class I, II, and III. Overjet is often associated with discrepancy of tooth size. ${ }^{15}$ Soh et al mentioned that the overjet with the most frequency in Melayu breeds is 3-5 $\mathrm{mm} \cdot{ }^{15,16} \mathrm{In} \mathrm{ABO}$ OGS points are given if there is an overjet of more than $1 \mathrm{~mm}$. Therefore, the success of treatment with the ABO system needs adjustment to the subjects studied because each race is proven to have its characteristics that are acceptable to a race.

In general, the success of orthodontic treatment at the Orthodontic Clinic of Airlangga University Dental Hospital is quite good. This is shown by the treatment in class I has a successful average of ABO OGS while in class II and III treatments in Orthodontic Clinic Dental Hospital, Faculty of Dental Medicine Universitas Airlangga has positive treatment progress.

In the anterior Bolton measurement statistic test has no difference between before and after treatment in malocclusion class I, II, and III. This may be due to at Orthodontic Clinic of Airlangga University Dental Hospital was not using the anterior Bolton ratio in orthodontic treatment planning. Lopatiene and Dumbravaite argue that the discrepancy of the size of the upper and lower teeth is an important factor to get good occlusion, overjet and overbite. ${ }^{15}$ Clinically anterior Bolton ratio is used to determine a case requiring interproximal reduction or increased tooth size with prosthetic restoration. This is in accordance with the results of ABO OGS results in this study which showed that overjet is a component with the highest average score in malocclusion class I, II, and III. Therefore, measurement of tooth size discrepancy needs to be considered to get a more appropriate treatment plan so that the success of treatment, especially in terms of overjet can get a better score.

ANB measurements before and after treatment found improved average results in each class although statistically showed no significant difference before and after treatment in class I, II, and III mallocation. Fakharian et al argue that the use of skeletal anchorage (miniplates and miniscrew) could be considered for some cases with dentoskeletal problems. ${ }^{8}$ Therefore the use of miniscrew in cases of dentoskeletal problems should be considered for optimal results.

Good facial aesthetics are often associated with the vertical dimensions, so a high proportion of the face is one of the important points to be aware of in the orthodontic treatment plan. ${ }^{17}$ In FHI measurements have been obtained a good average at the end of treatment in class I, II, and III although statistically only significant in class I. While in the measurement of UAFH:LAFH obtained statistically significant in class II. In class II there was an average increase in the height of the lower anterior face at the end of the treatment. Al Nimri's research stated that there was a significant increase in lower anterior facial height in class II division 1 malocclusion cases with the extraction of 2 premolars of the upper jaw. This is due to the movement of posterior teeth to mesial and extrusion in the first molar of the upper jaw. ${ }^{18,19}$ Nelson et al. stated that in cases of loss of anchoring in the upper jaw resulting in a backward rotational mandible resulting in an anterior lower facial height increase. ${ }^{20}$

Soft tissue profiles have a significant role in the diagnosis and treatment of orthodontics. Consideration of facial profiles is important because facial attractiveness has a psychosocial effect felt by patients. ${ }^{9}$ In this study, the average results of the E-line of the upper and lower lips tended to be more convex than the standard of Ricketts although at the end of treatment the average results improved in each class. In the study of E-line in java population by Oktaviona et al. ${ }^{9}$ obtained differences with the opinion of Ricketts. This suggests that acceptable facial profiles in the java population are different from the Rickets standard for Caucasoid people who tend to have a straight face. Each racial group has a different facial profile feature so it is not appropriate when in a diagnosis procedure and planning orthodontic treatment with standards from other races. Therefore, the success of the treatment needs to be matched on the facial profile of the closest racial groups, not to the average standard of value.

\section{CONCLUSION}

Analysis of the successful fixed orthodontic treatment in skeletal class I, II, and III skeletal malocclusions with ABO OGS measurement proved to be acceptable based on determining space requirements before treatment with the Bolton anterior index. In this study, it was proven that at the end of the treatment there was still a discrepancy in the ratio of the width of the six anterior teeth in class I, II, and III skeletal malocclusions. This is directly proportional to the results of the ABO OGS score, which shows that overjet is one of the components with the highest scores in class I, II, and III skeletal malocclusions. Therefore, measurement of the Bolton ratio to the anterior index needs to be done to get a better ABO OGS score. The highest ABO OGS score was class I skeletal malocclusion (18.93) followed by class III (20.75) and class II (22.93).

The success of fixed orthodontic treatment in correcting the proportion of lower anterior face height to total anterior facial height, skeletal discrepancies, and soft tissue before and after treatment using esthetic line measurements according to Ricketts is adequate. This is indicated by the mean value of the proportion of the upper and lower anterior face height in class I, II, and III malocclusions after treatment are nearly close to normal, namely 46\%:54\% and there was a statistically significant difference in class I malocclusion, also mean value of the upper and lower lip which improved in class I, II and III malocclusions. However, statistically significant differences were found only in lower lip esthetic lines in class II.

\section{REFERENCES}

1. Proffit WR, Fields HW, Sarver DM. Contemporary Orthodontics Ed.5. Canada: Mosby/Elsevier; 2018. 219 p. 
2. Assad A, Batool SI, Hasnain A, Faiza M. Malocclusion and its relationship with dental caries in a sample of Pakistani school children. Pak Oral Dent J. 2015;35(4):615-9.

3. Osman MA. classification of skeletal and dental malocclusion: revisited. StomaEduj. 2016;3(2):205-11.

4. Liu S, Oh H, Chambers DW, Baumrind S, Xu T. Validity of the American Board of Orthodontics Discrepancy Index and the Peer Assessment Rating Index for comprehensive evaluation of malocclusion severity. Orthod Craniofac Res. 2017 Aug;20(3):140-5.

5. Song G-Y, Baumrind S, Zhao Z-H, Ding Y, Bai Y-X, Wang $\mathrm{L}$, et al. Validation of the American Board of Orthodontics Objective Grading System for assessing the treatment outcomes of Chinese patients. Am J Orthod Dentofac Orthop. 2013 Sep;144(3):391-7.

6. Alamir G, Tsay TP, Manasse RJ. Reliability Study of the Bolton Analysis using Dental Models from Cases Passed by the American Board of Orthodontics Clinical Examination. J Dent Oral Disord. 2017;3(1):1053.

7. Subhashchandra PB. History of Orthodontics. New Delhi: Jaypee brothers medical; 2013. 15 p.

8. Fakharian M, Bardideh E, Abtahi M. Skeletal Class III malocclusion treatment using mandibular and maxillary skeletal anchorage and intermaxillary elastics: a case report. Dental Press J Orthod. 2019 Oct;24(5):52-9.

9. Oktaviona I, Ardani IGAW, Sjafei A. Hubungan tweed triangle dan posisi bibir terhadap garis estetik (Relationship between tweed triangle and the lips position to esthetic line). Dent J (Majalah Kedokt Gigi). 2014 Dec 1;47(4):220.

10. Hong M, Kook Y-A, Baek S-H, Kim M-K. Comparison of Treatment Outcome Assessment for Class I Malocclusion Patients: Peer Assessment Rating versus American Board of Orthodontics-Objective Grading System. J Korean Dent Sci. 2014 Jun 30;7(1):6-15.

11. Pyakurel U, Thapaliya KB, Gupta S, Gupta A, Dhakal J. Assessment of clinical cases using ABO discrepancy index. Orthod J Nepal. 2018 Dec 31;8(2):17-21.
12. Soh J, Sandham A, Chan YH. Occlusal status in Asian male adults: prevalence and ethnic variation. Angle Orthod. 2005 Sep;75(5):814-20.

13. Zapata-Noreña O, Carvajal-Flórez A, Barbosa-Liz D. Orthodontic treatment results evaluated for individual teeth according to the Objective Grading System. J World Fed Orthod. 2017 Mar;6(1):6-10.

14. Santiago JJ, Martínez CJ. Use of the Objective Grading System of the American Board of Orthodontics to evaluate treatment at the Orthodontic Graduate Program Clinic, University of Puerto Rico, 2007-2008. P R Health Sci J. 2012 Mar;31(1):29-34.

15. Lopatiene K, Dumbravaite A. Relationship between tooth size discrepancies and malocclusion. Stomatologija. 2009;11(4):119-24.

16. Dudnik O V, Mamedov AA, Dybov AM, Kharke V V, Kholmogorova P V. anthropometrical research of diagnistic models of jaws with the use of criteria of the end of orthodontic treatment (the american board of orthodontics (ABO)). Int Res J. 2017;3:62-9.

17. Yemitan TA, Oludare YS. Vertical Facial Height and its Correlation with Skeletal Pattern Among Young Nigerian Orthodontic Patients. Int J Dent Oral Sci. 2018 Aug 29;5(8):661-6.

18. Sayutia E, Sumantri Latif D. Evaluation of Lower Anterior Facial Height and Incisors Vertical Dimension after Class II Division 1 Treatment. Int J Med Sci Clin Invent. 2020 Jan 21;7(01):4686-90.

19. Hart TR, Cousley RRJ, Fishman LS, Tallents RH. Dentoskeletal changes following mini-implant molar intrusion in anterior open bite patients. Angle Orthod. 2015 Nov;85(6):941-8.

20. Heath EM, English JD, Johnson CD, Swearingen EB, Akyalcin S. Perceptions of orthodontic case complexity among orthodontists, general practitioners, orthodontic residents, and dental students. Am J Orthod Dentofacial Orthop. 2017 Feb;151(2):335-41. 